\title{
Reconsidering the Neighborhood Effect
}

Does Exposure to Residential Unemployment Influence Voters' Perceptions of the National Economy?

Bisgaard, Martin; Dinesen, Peter Thisted; Sønderskov, Kim Mannemar

Published in:

The Journal of Politics

DOI:

$10.1086 / 685088$

Publication date:

2016

Document version

Publisher's PDF, also known as Version of record

Citation for published version (APA):

Bisgaard, M., Dinesen, P. T., \& Sønderskov, K. M. (2016). Reconsidering the Neighborhood Effect: Does

Exposure to Residential Unemployment Influence Voters' Perceptions of the National Economy? The Journal of Politics, 78(3), 719-732. https://doi.org/10.1086/685088 


\title{
Reconsidering the Neighborhood Effect: Does Exposure to Residential Unemployment Influence Voters' Perceptions of the National Economy?
}

\author{
Martin Bisgaard, Aarhus University \\ Peter Thisted Dinesen, University of Copenhagen \\ Kim Mannemar Sønderskov, Aarhus University
}

\begin{abstract}
The state of the national economy often directs voting. But how do citizens form perceptions of a complex and abstract macroeconomy? This study examines whether exposure to unemployment in citizens' immediate residential surroundings shapes their perceptions of the national economy. Using novel data tapping the official proportion of unemployed people residing within radii between 80 and 2,500 meters of an individual's place of residence, we confront common methodological and theoretical challenges in existing work. Findings show that citizens do rely on cues from their residential microcontexts when forming perceptions of the national economy. Furthermore, we provide evidence that measures of unemployment in more aggregate contexts are not only poor reflections of what individuals are likely to experience in their immediate neighborhood but also seem to capture a different mechanism related to local media exposure.
\end{abstract}

C itizens' perceptions of the state of the national economy are consequential for electoral behavior. According to a vast number of studies, citizens punish and reward the incumbent government based on how the national economy is performing (for recent reviews, see LewisBeck and Stegmaier [2007] and Linn, Nagler, and Morales [2010]). However, if citizens are to hold incumbents accountable for economic conditions in any meaningful way, a crucial question is how perceptions of the national economy are formed in the first place (Ansolabehere, Meredith, and Snowberg 2011; Conover, Feldman, and Knight 1987). At the heart of this question lies one premise: the national economy is an abstract and inherently unobservable phenomenon (Mutz 1998; Stevenson, and Duch 2013). Thus, it may not come as a surprise that citizens arrive at very different conclusions about the same macroeconomy (e.g., Duch, Palmer, and Anderson 2000; Kramer 1983), that they let their party loyalties bias such assessments (e.g., Bartels 2002; Bisgaard 2015; Evans and
Andersen 2006), and that they rely on elite actors, for example, the news media, to guide and sometimes misguide them (e.g., Goidel and Langley 1995; Hetherington 1996; Soroka 2006). In this study, we examine an important alternative source of perceptions of the national economy: citizens' immediate residential surroundings.

The notion that citizens may obtain and rely on information from their social environment more generally, and their residential surroundings more specifically, is hardly new (e.g., Baybeck and McClurg 2005; Huckfeldt and Sprague 1987; Lazarsfeld, Berelson, and Gaudet 1944). In fact, mounting evidence suggests that local economic conditions, whether measured at the level of counties (Reeves and Gimpel 2012), metropolitan areas (Weatherford 1983), zip-codes (Newman et al. 2014), or census tracts (Anderson and Roy 2011), all shape voters' macroeconomic outlooks (see also Ansolabehere, Meredith and Snowberg 2014). Such findings are of crucial importance because they suggest that citizens' concep-

Martin Bisgaard (mbisgaard@ps.au.dk; corresponding author) is a PhD student at the Department of Political Science, Aarhus University, Denmark. Peter Thisted Dinesen (ptd@ifs.ku.dk) is professor (MO) at the Department of Political Science, University of Copenhagen. Denmark. Kim Mannemar Sønderskov (ks@ps.au.dk) is professor at the Department of Political Science, Aarhus University, Denmark.

Financial support for geocoding the survey data and acquiring the register data was provided by the VELUX foundation, the Carlsberg foundation, and the Danish Council for Independent Research (Social Sciences). The register data used in this study contain sensitive personal information, and access to the data is therefore restricted to users authorized by Statistics Denmark. Information on data access, the files used to perform the analyses, as well as the logged output from these analyses are available in the JOP Dataverse (https://dataverse.harvard.edu/dataverse/jop). An online appendix with supplementary material is available at http://dx.doi.org/10.1086/685088.

The Journal of Politics, volume 78, number 3. Published online May 20, 2016. http://dx.doi.org/10.1086/685088

(C) 2016 by the Southern Political Science Association. All rights reserved. 0022-3816/2016/7803-0007\$10.00 
tions of abstract political issues are not merely a result of how elites "orchestrate" and potentially "distort" reality (Kinder and Kiewiet 1981, 157) but also reflect what citizens themselves experience as a by-product of observing or interacting with others in their everyday lives (Popkin 1991).

However, while geography is a straightforward way to delineate the fluid concept of a social context, most measures previously used tend to cover large and arbitrary geographical areas. As a consequence, they can only work as crude containers of the myriad of experiences that individuals' local environments may give rise to, for example, near their place of residence, at their workplace, or in local associations. There is thus little way of knowing whether the effect of these aggregate contextual measures really reflects social influence occurring in a localized environment, and even less so, what type of social network in this environment that matters (for recent treatments of this, see Dinesen and Sønderskov [2015], Moore and Reeves [2015], and Wong et al. [2012]). Somewhat ironically, what scholars have uncovered so far could be something quite different from experiences stemming from citizens' social context, namely, mass mediated influence (Mutz 1998). This is so because the geographical boundaries of oft-used contextual measures happen to covary with the boundaries of local news media markets (Books and Prysby 1999). Thus, the original question stands: Do voters infer the state of the national economy from exposure to social cues in their local environments?

We address these questions by merging survey data on perceptions of the state of the economy with detailed information about unemployment in a respondent's local environment. In doing so, we narrow in on one specific aspect of the local context: the immediate neighborhood. While people are embedded in different social contexts, most are arguably exposed to their immediate neighborhood on a daily basis (Baybeck and McClurg 2005). This makes the immediate residential context relevant to almost all citizens. To measure this context, we use administrative data from the national Danish registers that contain detailed information about everyone legally residing in Denmark, including the exact geographical location of their residence, their unemployment status, and a range of other characteristics. The geographic information enables us to identify how far any given resident lives from any other resident. As a consequence, we are able to construct multiple measures capturing the exact proportion of unemployed people residing within a respondent's residential area of a given size. Specifically, we use circles with radii between 80 and 2,500 meters centered around each respondent's place of residence. Employing this measure for the most narrow contexts permits a more direct test of whether citizens consider social cues from their im- mediate residential surroundings when forming impressions of the national economy. Furthermore, zooming out to more aggregate residential contexts-that resemble more the contextual units used in previous research-we can address how well aggregate measures capture what citizens are exposed to in their immediate residential context or if such measures capture more aggregate phenomena.

Our analyses yield two important insights. First, we find that the proportion of unemployed people residing in the most immediate neighborhood (within a radius from 80 to 250 meters of the respondent's place of residence) significantly predicts perceptions of national economic conditions when we control for unemployment measured at more aggregate levels (within a radius of 2,500 meters), municipality characteristics, political ideology, and a host of other individual as well as contextual characteristics, including unemployment within an individual's household. This is strong evidence that exposure to unemployment in the immediate residential surroundings informs individuals' evaluations of the national economy. Second, when gradually aggregating the size of the residential area from a radius of 80 to 2,500 meters, we find that more aggregate measures of contextual unemployment are not only poor reflections of the immediate residential context but are in fact better proxies for unemployment at the municipality level. $\mathrm{Mu}$ nicipalities are populous and spatially large political entities, ${ }^{1}$ and they are often delineated by similar geographical boundaries as local news media outlets. Consequently, aggregate measures of contextual unemployment most likely capture local news media coverage rather than what people observe in their residential surroundings.

\section{NEIGHBORHOOD EXPOSURE AND INFERENCES ABOUT NATIONAL PHENOMENA}

Forming perceptions of collective phenomena such as the national economy is a daunting task, not least because the true state of the national economy is complex, abstract, and not directly observable (Aidt 2000; Mutz 1998; Stevenson and Duch 2013). Thus, in trying to grasp economic conditions, voters may quite naturally resort to strategiesrational or not-that reduce informational complexity. For example, they may look to whether or not their party holds office (e.g., Bartels 2002; Bisgaard 2015; Gerber and Huber 2010) or rely on recent news media coverage in forming perceptions of the macroeconomy (e.g., Boomgaarden et al. 2011; Goidel and Langley 1995; Hetherington 1996; Soroka 2006).

1. Municipalities are the smallest political units in Denmark. On average, they are 558 square kilometers and contain 56,476 inhabitants. For a more detailed description of Danish municipalities, see appendixes B and C. 
However, another line of work has turned attention to an alternative source of information about the state of the national economy: the individual's social context (Anderson and Roy 2011; Books and Prysby 1999; Mondak, Mutz, and Huckfeldt 1996; Newman et al. 2014; Reeves and Gimpel 2012; Weatherford 1983). Building on theories of social influence (e.g., Huckfeldt and Sprague 1987; Lazarsfeld et al. 1944), a central theoretical mechanism stipulated in this work is that voters obtain economically relevant information through "the slow drip of everyday life" (Baybeck and McClurg 2005, 498) by casually observing or directly interacting with others in various social contexts (Cho and Rudolph 2008; Huckfeldt and Sprague 1987). For example, in learning about neighbors or coworkers having lost their jobs, one may reason that the underlying cause is not necessarily due to a lack of personal effort but rather a societal problem such as a poorly performing national economy. Since socially diffused information is acquired as a by-product of people's everyday lives and by definition entails information about others, people may be particularly prone to rely on this information when judging mass collectives (Weatherford 1983; see also Ansolabehere et al. 2014; Popkin 1991).

Information from an individual's social context could also influence judgments about national phenomena through more subconscious and automatic processes. Passively and routinely noting financial distress in one's social surroundings would likely increase the accessibility of negative economic considerations. Thus, in line with work on accessibility bias in cognitive psychology (e.g., Higgins and King 1981), considerations that are more accessible in memory are more likely to influence subsequent inferences. When asked to evaluate national economic conditions, different considerations may therefore automatically come to mind for people who are routinely exposed to unemployment compared to people who are not (see also Iyengar and Kinder 1987; Miller and Peterson 2004; Zaller 1992). Perhaps without realizing it, people may draw inferences about national phenomena based on the social stimuli they are exposed to on a daily basis.

Whether the underlying mechanism is apprehensive or more subconscious in nature, both accounts point to the fact that voters may likely infer the state of the national economy from their social contexts.

\section{MEASURING THE UNMEASURABLE? RESIDENTIAL CONTEXTS AND THE ISSUE OF AGGREGATION}

While the notion that individuals are influenced by their social environments is plausible, providing a rigorous empirical test of this argument is more challenging. Besides the issue that people are exposed to social contexts in nonran- dom ways (an issue we return to), a central challenge is measurement (Dinesen and Sønderskov 2015; Healy and Lenz 2014; Hopkins 2010; Moore and Reeves 2015; Oliver and Mendelberg 2000; Wong et al. 2012)

Social context is a multifaceted phenomenon that can be construed in a number of ways, for example, as relations with friends and family or as more superficial encounters with neighbors, coworkers, and others we meet in our daily life. Despite its many incarnations, a common measurement strategy within political behavioral research has focused on where people live. This arguably reflects the ubiquity of the neighborhood in most people's lives: "People may travel further distances in their day-to-day lives, but they are still rooted at a residence, which, of course, is located in the social and geographic location of the neighborhood," as Baybeck and McClurg $(2005,495)$ write.

Despite the alleged importance of the residential setting, previous research has been limited in verifying this empirically due to the unavailability of detailed, objective data on whom an individual actually lives around and therefore is likely to encounter in his or her neighborhood. Instead, scholars have been forced to measure the residential context using predefined administrative units measured at relatively high levels of aggregation (Anderson and Roy 2011; Newman et al. 2014; Reeves and Gimpel 2012; Weatherford 1983). For example, while a census tract is a fairly disaggregate unit, it varies considerably in spatial as well as population size (in some cases, a census tract contains between 2,500 and 8,000 residents [Anderson and Roy 2011]). This in turn implies that counties and other aggregate contextual units are at best noisy proxies for what people may observe at their place of residence. Clearly, such areas are likely internally heterogeneous with regard to their social composition, which in turn means that individuals can live in one residential area that is quite different from the county or census tract at large (Dinesen and Sønderskov 2015; Moore and Reeves 2015). ${ }^{2}$ As a consequence of their expansiveness, aggregate measures of place are typically assumed to capture the local context in toto, and therefore they include a host of different social influences potentially operating within the ag-

2. As an alternative to objective geographical data, others have turned to the use of self-reported measures (Mondak et al. 1996; see also Baybeck and McClurg 2005; Newman et al. 2014). While these studies confirm that individuals are attentive to their residential surroundings, utilizing such measures to explain a person's perception of the national economy is problematic for other reasons: self-reported neighborhood experiences are likely endogenous to an individual's macroeconomic outlook and, since both typically stem from the same survey, the correlation between the two is likely to be upward biased due to common method bias (e.g., a response style leading respondents to answer appraising questions in a similar manner; Podsakoff et al. 2003). 
gregate context, including the immediate residential area, the workplace, and so forth (e.g., Anderson and Roy 2011; Reeves and Gimpel 2012). While this is obviously an important first step in establishing the importance of the local environment for perceptions of the national economy, we would ideally be able to parse out in more detail whether and how specific aspects of this context matter. In line with this ambition, this paper singles out the immediate residential surroundings in order to examine whether exposure to cues about unemployment in the proximate neighborhood informs perceptions of the national economy.

Finally, and somewhat ironically, predefined administrative units could simply capture something rather different than social influence stemming from the local environment, namely, mass-mediated influence (Mutz 1992). Since predefined administrative units covary-or are even collinearwith political boundaries such as cities and counties, an observed spatial relationship may stem from attentiveness to political debate and local news media coverage that happen to occur within the same geographical space (Books and Prysby 1999; see also Reeves and Gimpel 2012).

Overall, then, there is little direct evidence to suggest that voters infer national economic conditions from what they are exposed to near their place of residence. On the pages that follow, we present an approach to measurement and design that exploits the fact that exposure to other individuals in one's immediate residential surroundings is essentially unavoidable. More specifically, we construct highly detailed measures of unemployment in a respondent's residential microcontext, down to a radius of 80 meters from the place of residence.

\section{DATA AND DESIGN}

In order to examine whether individuals infer national economic conditions from their residential microcontexts, we merge five rounds of nationally representative cross-sectional survey data with official data from the national Danish registers. The data hold two crucial features for our purposes. First, as we describe in greater detail below, the finegrained measure tapping unemployment within an individuals' microcontext varies at a very low geographical level. Thus, in contrast to previous studies, we can limit the comparison to citizens who experience different microcontexts but live within the same local political entities, thereby ruling out the impact of other influences not stemming from social diffusion, for example, local news media coverage. Second, by relying on official unemployment data to construct measures of microcontextual unemployment, we avoid common problems of using self-reported data, for example, undereporting of unemployment due to the social stigma asso- ciated with this (i.e., social desirability bias). The detail of the data thus gives an ideal basis for examining whether individuals' most immediate residential surroundings really influence their perceptions of the national economy.

Still, any observational study of context is challenged by the possibility of selection bias or omitted variable bias, that is, the possibility that individuals with certain characteristics (choose to) live in certain contexts, which may lead to biased estimates (Bishop 2013; Egan and Mullin 2012; Hopkins 2010). Our study is no exception, as residential choice may be correlated with characteristics that also affect perceptions of the national economy, such as partisanship and income. If these characteristics remain unobserved, the estimated relationship is potentially biased and may therefore lead to flawed conclusions regarding the (lacking) influence of residential context. To minimize such bias, we include the respondent's own unemployment status, gender, age, level of education, disposable income, length of residence at current address, population density in the residential area, newspaper exposure, political interest, and self-placement on a political left-right scale as control variables. ${ }^{3}$ All variables, except for political left-right orientation, political interest, and newspaper reading, are obtained from the national registers and are thus based on objective and reliable information. Furthermore, we control for whether any person within a respondent's household is registered as unemployed to separate the neighborhood context effect from that of the household.

In addition to the control variables described above, we include time and municipality fixed effects in the models. These are included to rule out confounding by timeinvariant phenomena varying at the municipality level, for example, local political factors, as well as media structure, and national phenoman varying over time, for example, the economic turmoil in the wake of the financial crisis.

Needless to say, the rich set of reliably measured control variables does not rule out bias from self-selection. However, the administrative data provide us with some leverage in addressing self-selection on unobservables by examining patterns of relocation and staying put in a given residential

3. Denmark was governed by a right-wing government throughout the studied period, so the left-right measure picks up support for the incumbent government. In this regard, it bears notice that controlling for a respondent's partisanship when estimating the effect of residential unemployment may represent a "bad control problem" (Angrist and Pischke 2008, 64). Because your party affiliation is less likely to affect your neighbor's unemployment status than vice versa, we are potentially controlling for a mediator. Yet, in order to follow existing work and to hold constant potential confounding factors that are proxied by a respondent's partisanship, we report results from models including this variable. Appendix F reports the results from such less restricted models. 
area based on prior perceptions of the national economy (see Putnam 2007; Rudolph and Popp 2010). The test suggests that this is not the case and thus that this form of self-selection is an unlikely explanation for the observed patterns (see appendix D for more detail; appendices A-J are available online).

\section{Measuring the immediate neighborhood}

We measure our main independent variable, unemployment within the immediate residential context, using official unemployment data from the national Danish registers. The registers contain very detailed longitudinal information about all individuals legally residing in Denmark, including the exact geographical location of their residence, unemployment status, and a range of other characteristics (see Thygesen et al. 2011). The geographic information allows us to identify how far any given resident lives from other residents. Coupled with register data on residents' unemployment status, we can thus compute the exact share of unemployed people living within any given (geodesic) distance of a given individual.

For each survey respondent, we calculated the share of unemployed adults residing within contexts varying from 80 to 2,500 meters in radius (262-8,202 feet) discounting the individual herself/himself. ${ }^{4}$ We chose the 80 meter radius as the smallest context based on the assumption that most people would plausibly be exposed to most residents within that area from time to time. In principle, the choice of the specific radius of the context is arbitrary, but we chose a radius of 80 meters as the smallest context because even smaller areas may contain very few people. Basing the measure on only a few neighbors would increase its sensitivity to the exact size of context since inclusion/exclusion of additional neighbors could therefore lead to dramatic changes in the measure. ${ }^{5}$ Needless to say, we cannot be sure that people are in fact exposed to everyone within an 80 meter radius, but our microcontextual measure arguably constitutes a more accurate picture of whom people are exposed to in their residential settings than more aggregate contexts.

The flexible nature of our data enables us to assess whether the results are sensitive to alternative definitions of

4. Currently our data contain the distance between each respondent and the residents living in the 20,000 nearest households ( $>550,000,000$ observations). This effectively limits the radius to 2,500 meters for respondents living in densely populated areas.

5. This also led us to exclude respondents with fewer than 10 persons in their 80 meter context, which effectively excludes respondents living in remote areas (13.5\% of the sample). The general results of the analyses reported below are not affected by including/excluding these respondents (see appendix E). a respondent's immediate context, for example, a radius of 130, 180, or 250 meters. Consequently, it also allows us to examine whether more geographically aggregate measures actually capture characteristics of people living near a respondent's place of residence. In other words, how much out of focus is the picture of a person's immediate context when we gradually zoom out and aggregate the contextual measure to levels of aggregation that more resemble the measures employed in previous research?

Figure 1 speaks directly to these questions. First, panel $A$ shows how much the aggregate unemployment rate (obtained in the 2,500 meter context) deviates from the unemployment rate observed in an individual's immediate context (the 80 meter context). Here, negative deviations indicate that aggregate unemployment is below what is observed in the immediate residential context. The nonshaded areas in the figure give the percentage of cases where this deviation in unemployment rates is more than $+/-5$ percentage points. As can be seen from the figure, aggregate measures can severely mischaracterize an individual's residential microcontext: for $19 \%$ of the individuals in the sample, the aggregate measure understates the residential unemployment rate by more than 5 percentage points; for $37 \%$ of the sample, the aggregate measure overstates residential unemployment by more than 5 percentage points. Thus, for over half of the sample, the aggregate unemployment rate is very far from what individuals are likely exposed to in their immediate neighborhoods.

Second, the fact that aggregate measures can be poor reflections of people's microcontexts is further supported by the solid line in panel $B$, figure 1 . It shows the $R$-squared from a set of bivariate regression models where unemployment in the 80 meter context has been regressed on the unemployment rates of more aggregate contexts of varying size. Thus, the solid line shows how well geographically aggregate measures reflect a respondent's most immediate residential setting. As witnessed by the solid line, the proportion of variance that is explained by the more aggregate measures drops at an extremely fast rate. For example, if one increases the radius from just 80 meters to 500 meters, the explained proportion of variance drops by almost 70 percentage points. In other words, when we know the exact proportion of unemployed people living in a radius of 500 meters from the respondent's residence, we only become around 30 percentage points better at predicting the proportion of unemployed people living near the respondent compared to just guessing on the sample mean. In fact, in contexts of about 1,500 meters or wider, the aggregate contextual measure becomes a better proxy for the municipality unemployment rate than unemployment in the immediate vicinity 

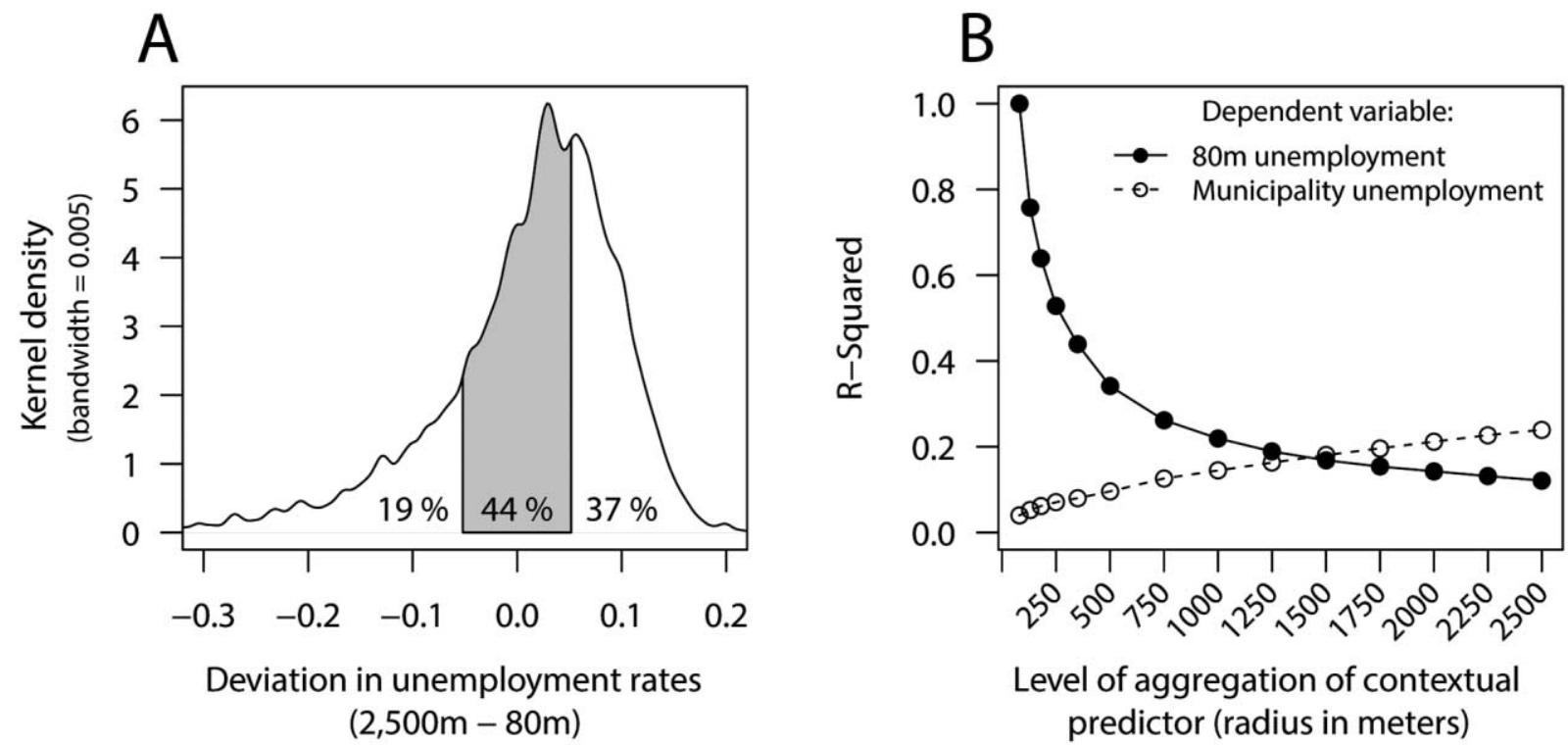

Figure 1. Panel $A$ shows how much the aggregate contextual measure of unemployment (2,500 meters) deviates from the unemployment rate observed in the immediate context (80 meters). The nonshaded areas mark the share of the distribution that lies above or below a nontrivial deviation in unemployment rates, that is, $+/-5 \%$. Panel $B$ shows the $R$-squared or explained variance when using each of the contextual unemployment rates to explain unemployment in the immediate context (solid line) and in the municipality (dashed line). The analysis is based on the respondents in our sample $(N=6,567)$.

of an individual's place of residence. This is shown by the dashed line in the figure, which gives the $R$-squared from similar models but with the municipality unemployment rate as the dependent variable.

Seen in relation to extant work, this is important evidence of aggregate measures being poor proxies for an individual's residential microcontext (see also Dinesen and Sønderskov 2015). Thus, geographically more aggregate measures appear unlikely to capture processes of social influence occurring within the immediate neighborhood. Obviously, this raises the question of what such measures are actually capturing - a question we will return to later.

\section{Survey data on the dependent variable}

In order to address the central question of whether characteristics of the residential microcontext influence voters' perceptions of the national economy, we merge the abovedescribed measures with the first five rounds of the Danish version of the European Social Survey (ESS), a nationally representative survey conducted in 2002-3, 2004-5, 2006-7, 2008-9, and 2010-11. ${ }^{6}$ The respondents in the Danish version of the ESS were randomly sampled from the national civil registry, and their civil registration numbers are retained

6. The ESS is generally held to be a highly valid and reliable data source of survey data on political and social attitudes in Europe (Norris 2004). The response rate varies between $51 \%$ and $68 \%$ in the five surveys, and all interviews are conducted face-to-face at the respondent's address. Further information about the sampling and fieldwork can be found in the Survey Documentation Reports at the ESS (2014) website. by the data collection agency, which enables us to link individual and contextual sociodemographic information from the Danish national registers to each respondent. From the ESS, we obtain the study's central dependent variablevoters' perceptions of the national economy. The variable is measured using the following question: "On the whole, how satisfied are you with the present state of the economy in Denmark?" It is measured on an 11-point scale ranging from 0 (extremely dissatisfied) to 10 (extremely satisfied), but it is rescaled from 0 to 1 in the analysis. Further details can be found in appendix A.

In the analysis, the measure tapping perceptions of the national economy is assumed continuous, and it is modeled using ordinary least squares (OLS) regression.

\section{RESULTS}

First, we address the main question of whether exposure to unemployment in the immediate residential surroundings influences perceptions of the national economy. If people infer the state of the macroeconomy from what they observe in their local contexts, we would expect that individuals who are surrounded by a higher proportion of unemployed neighbors would on average evaluate the national economy more negatively than individuals who are surrounded by a relatively lower proportion of unemployed people.

Table 1 shows the estimates from three different linear regression models in which perceptions of the national economy have been regressed on the local unemployment rate within an 80 meter radius of the respondent's place of 
Table 1. The Effect of the Local Unemployment Rate (within 80 Meters of the Respondent's Place of Residence) on Perceptions of National Economic Conditions While Controlling for the Broader Context $(2,500$ Meters) as Well as Individual-Level Characteristics

\begin{tabular}{|c|c|c|c|}
\hline & Model 1 & Model 2 & Model 3 \\
\hline Local unemployment rate ( 80 meters) & $\begin{array}{r}-.070^{*} \\
(.030)\end{array}$ & $\begin{array}{r}-.072^{*} \\
(.031)\end{array}$ & $\begin{array}{r}-.064^{*} \\
(.031)\end{array}$ \\
\hline Local unemployment rate (2,500 meters) & & $\begin{array}{c}.029 \\
(.103)\end{array}$ & $\begin{array}{c}.023 \\
(.103)\end{array}$ \\
\hline Unemployment within household & & & $\begin{array}{r}-.023^{\star} \\
(.010)\end{array}$ \\
\hline Own unemployment status & $\begin{array}{c}-.052^{\star * *} \\
(.009)\end{array}$ & $\begin{array}{c}-.052^{\star * *} \\
(.009)\end{array}$ & $\begin{array}{c}-.050^{\star * *} \\
(.009)\end{array}$ \\
\hline Population (80 meters) & $\begin{array}{c}-.000^{\star *} \\
(.000)\end{array}$ & $\begin{array}{c}-.000^{\star *} \\
(.000)\end{array}$ & $\begin{array}{c}-.000^{\star *} \\
(.000)\end{array}$ \\
\hline Age & $\begin{array}{c}.000 \\
(.000)\end{array}$ & $\begin{array}{c}.000 \\
(.000)\end{array}$ & $\begin{array}{c}.000 \\
(.000)\end{array}$ \\
\hline Years of education & $\begin{array}{c}.002^{*} \\
(.001)\end{array}$ & $\begin{array}{c}.002^{*} \\
(.001)\end{array}$ & $\begin{array}{c}.002^{\star} \\
(.001)\end{array}$ \\
\hline Male & $\begin{array}{l}.045^{\star * *} \\
(.005)\end{array}$ & $\begin{array}{l}.045^{\star * *} \\
(.005)\end{array}$ & $\begin{array}{l}.046^{\star * *} \\
(.005)\end{array}$ \\
\hline Income (in $100.000 \mathrm{DKR}$ ) & $\begin{array}{c}.004^{*} \\
(.002)\end{array}$ & $\begin{array}{c}.004^{\star} \\
(.002)\end{array}$ & $\begin{array}{c}.004^{\star} \\
(.002)\end{array}$ \\
\hline Years lived at location & $\begin{array}{c}.000 \\
(.000)\end{array}$ & $\begin{array}{c}.000 \\
(.000)\end{array}$ & $\begin{array}{c}.000 \\
(.000)\end{array}$ \\
\hline Right wing & $\begin{array}{l}.166^{\star * *} \\
(.013)\end{array}$ & $\begin{array}{l}.166^{\star * \star} \\
(.013)\end{array}$ & $\begin{array}{l}.166^{* * *} \\
(.013)\end{array}$ \\
\hline Newspaper exposure & $\begin{array}{c}-.008 \\
(.017)\end{array}$ & $\begin{array}{r}-.008 \\
(.017)\end{array}$ & $\begin{array}{c}-.009 \\
(.017)\end{array}$ \\
\hline Political interest & $\begin{array}{c}-.009^{*} \\
(.004)\end{array}$ & $\begin{array}{r}-.009^{*} \\
(.004)\end{array}$ & $\begin{array}{c}-.009^{\star} \\
(.004)\end{array}$ \\
\hline Constant & $\begin{array}{l}.602^{\star * *} \\
(.023)\end{array}$ & $\begin{array}{l}.598^{* * *} \\
(.028)\end{array}$ & $\begin{array}{l}.601^{\star * *} \\
(.028)\end{array}$ \\
\hline Municipality fixed effects & Yes & Yes & Yes \\
\hline Time fixed effects & Yes & Yes & Yes \\
\hline Adusted $R^{2}$ & .179 & .178 & .179 \\
\hline$\sigma$ & .197 & .197 & .197 \\
\hline
\end{tabular}

Note. The table presents unstandardized OLS regression estimates; standard errors are in parentheses. Number of observations $=6,101$; number of survey rounds $=5$; number of municipalities $=314$. During the studied period, an administrative reform reduced the number of municipalities from 275 to 98 . The table reports 317 municipalities, because some municipalities were left unchanged by the reform and because a few municipalities are excluded due to a lack of survey data. All variables of primary interest are scaled from 0 to 1 .

${ }^{\star} p<.05$, two-sided test.

${ }^{* *} p<.01$, two-sided test.

${ }^{* * *} p<.001$, two-sided test.

residence. As can be seen from model 1, the unstandardized regression coefficient of the microcontextual unemployment rate $(80$ meters $)$ is .07 , and it is significant $(p<.05)$. Thus, when the broader context is held constant, that is, municipality- and time-specific characteristics (by means of fixed effects) as well as a host of individual-level variables, there is a significant effect of living around more unem- ployed people. ${ }^{7}$ Furthermore, as evidenced by model 2, this estimate is not affected even when we hold constant un-

7. In appendix $\mathrm{F}$, we provide an overview of how sensitive the marginal effect of the local unemployment rate is to including various control variables. As shown in the appendix, the estimated marginal effect of the local unemployment rate is primarily affected by introducing individuallevel characteristics. 
employment measured at a radius of 2,500 meters. More importantly, even when unemployment within a respondent's household is held constant in model 3, the overall findings still hold up. In other words, the fact that the effect of microcontextual unemployment is not simply accounted for by individual-level differences and characteristics of the broader context suggests that exposure to unemployed people in the immediate neighorbood informs perceptions of the national economy.

Turning to the effect size of the local unemployment rate (80 meters), a respondent's satisfaction with the national economy was found to drop by about 7 percentage points when we compare a microcontext where no one is unemployed to a context where everyone is unemployed. In appendix $G$, we compare this effect to other variables at different observed ranges. ${ }^{8}$ While the marginal effect of the microcontextual unemployment is, roughly speaking, comparable to the effect of becoming unemployed oneself, as well as the effect of income, it is consistently below the effect of left-right orientation for every observed range of the variables. Thus, while the effect of microcontextual unemployment is substantively meaningful, it is still smaller than the effect of left-right orientation, which, judging from extant work, is also to be expected (e.g., Reeves and Gimpel 2012) perhaps even more so considering the fact that left-right orientation is self-reported and stems from the same survey as the dependent variable (i.e., the correlation between the two variables is likely biased upwards).

Thus, to this point, our findings suggest that a central theoretical mechanism stipulated in extant work is valid: voters do appear to consider their most immediate surroundings when forming perceptions of the national economy.

\section{How sensitive are the results?}

Next, we probe the sensitivity of the result to the exact size of the context. If voters' perceptions of national economic conditions are really shaped by a process of social influence, that is, by face-to-face interaction or casual observation of others, one would expect to find significant relationships between contextual unemployment and economic perceptions at relatively low radii. Therefore, we expect to find roughly similar contextual effects in small contexts.

Figure 2 confirms this expectation. The black dots show the marginal effect of a change from the 1st to 99th per-

8. For employment within an 80 meter radius, the minimum and maximum observed range is 0 to 1 (the effect size is 0.064 units on a onepoint scale). the 1 st to 99 th percentile is 0 to .44 (effect size is 0.028 ), and the 5 th to 95 th percentile is .1 to 3 (effect size is 0.013 ). All effect sizes are based on model 3 reported in table 1 .

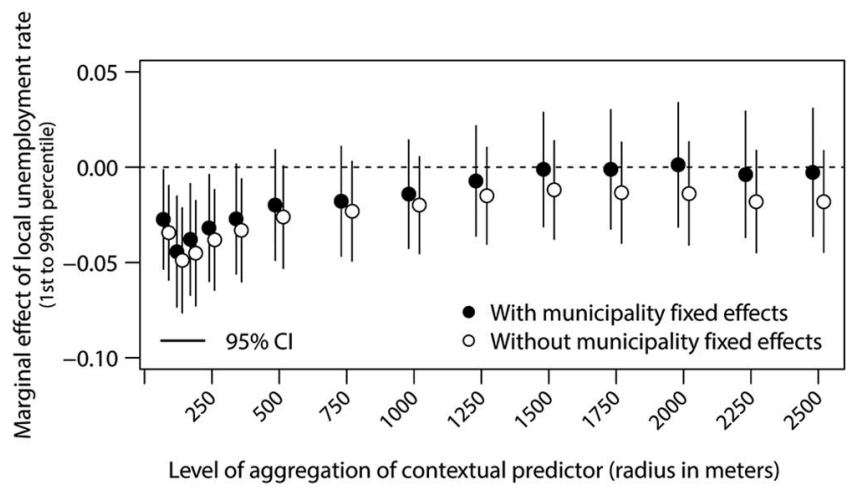

Figure 2. The marginal effects of the local unemployment rates measured at radii ranging from 80 to 2,500 meters on perceptions of the national economy. The effects are based on a change from the 1st to the 99th percentile on the unemployment measures, when each unemployment measure is entered into separate models. The black dots represent the marginal effect for a model specification with municipality fixed effects and the hollow dots give the marginal effect of the local unemployment rate without municipality fixed effects. All models include the same control variables as model 3 in table 1 except for unemployment measured in contexts of a radius of 2,500 meters. Moreover, population density is measured in contexts with the same radius as the local unemployment rate.

centile in the local unemployment rate from models with the same specification as model 3 in table 1 , except that the spatial size of the context is varied between 80 and 2,500 meters (thus, the models only include one context at a time). The left-most black dots show that we obtain similar effects when the local unemployment rate is measured in contexts with radii between 80 and 250 meters. This shows that the results are robust to slightly different demarcations of the immediate residential setting.

However, as the geographic unit of analysis is aggregated even further, the effect starts to attenuate. The attenuation toward zero is what we would expect if perceptions of the national economy are affected by exposure to unemployed people in one's immediate neighborhood, since the unemployment rate in more aggregate contexts is an increasingly poor measure of the unemployment actually experienced in the microcontext. Thus, the pattern displayed by the black dots provides additional support for perceptions of the national economy being affected by the social cues received in the immediate residential context.

Nevertheless, seen in relation to prior work, the black dotted point estimates depicted in figure 2 raise a puzzle: Why do extant studies recover an effect of contextual unemployment despite the fact that they are typically based on contexts that are much more aggregated than even the largest one used here? According to our estimates, the contextual effect of unemployment is virtually zero when the context is larger than a circle with a radius of 1,500 meters. 
The hollow dots in figure 2 suggest one explanation. They show the marginal effect of contextual unemployment estimated without municipality fixed effects. As can be seen from the left-most part of the figure, the marginal effect of unemployment measured at low levels of aggregation, in radii between 80 and 250 meters, is virtually unaffected when municipality fixed effects are excluded from the model. However, when we move to higher levels of aggregation, the two patterns diverge: the effect of unemployment does not attenuate to the same extent as in models excluding municipality fixed effects. Thus, when we do not hold municipalitylevel factors constant, we also find tentative evidence for the effect of aggregate-level unemployment similar to previous studies. ${ }^{9}$ Moreover, the difference between the estimates in the larger context with and without municipality fixed effects suggests that the effect in larger contexts comes about because of phenomena varying at the municipality level. This is also supported by the finding that the correlation between municipality-level unemployment and residential unemployment increases in larger residential contexts, as seen in panel $B$ of figure 1 . So when previous studies have found a correlation between aggregate measures of unemployment and perceptions of the national economy, it may not be because aggregate measures of unemployment reflect the social cues that individuals receive from observing and interacting with others in their immediate residential context. Rather, the effect likely reflects a response to more aggregate and distant phenomena that individuals can only grasp through mediated information. Below, we address one plausible explanation in this regard: local news media.

\section{What mechanisms are aggregate contextual measures capturing?}

Since the aggregate contexts often correspond to political entities, one could hypothesize that aggregate effects could be ascribed to information acquired through media coverage rather than direct social interactions (Books and Prysby 1999). For example, political entities, such as municipalities in the Danish setting, may roughly correspond to the same geographical boundaries characterizing local news media markets. We can assess this interpretation through one observable implication: if aggregate measures are capturing a mechanism related to local news media coverage, and if local media provide information about the local economic situa-

9. Although the marginal effect of unemployment measured at a radius of 2,500 meters is not statistically significant at conventional levels, it is fairly close ( $p=.18$, two-tailed test). This slight deviation from findings presented in extant work is likely due to differences in statistical power. For example, in their study, Reeves and Gimpel (2012) analyze around 32,700 respondents. tion, we should expect aggregate contexts to matter more to individuals who are more prone to follow local news sources and thus obtain information about, inter alia, municipalitylevel unemployment, which cannot be observed directly.

Danish local media indeed report information on local economic conditions (Lund 2002), although perhaps to a lesser extent than media in the United States (Iyengar et al. 2010). They are also an important source of information about local politics (Elmelund-Præstekær and Hopman 2013). As a consequence, we expect the prediction that aggregate contexts matter more for people who follow local news media to be borne out in the Danish setting.

There is a range of questions tapping the level of exposure to different news outlets in the ESS, specifically television, radio, and newspapers (ESS 2014). While all of these outlets are represented regionally, and sometimes more locally, newspapers remain one of the most frequently used and respected information sources when it comes to local politics in Denmark (Buch and Levinsen 2007; Serritzlew and Mortensen 2007). Furthermore, communication research has consistently found that people absorb more politically relevant information from newspapers as opposed to, for example, broadcast and tabloid news sources (e.g., Delli Carpini and Keeter 1996; Fraile and Iyengar 2014; Newton 1999; Price and Zaller 1993; Robinson et al. 1986). Thus, to sum up, if aggregate contextual unemployment matters for voters' perceptions of the national economy because these larger contexts tend to covary with local news media markets, then one would expect aggregate contexts to matter more to individuals who are exposed the most to such information. In our model, this prediction implies a significant interaction term between aggregate contextual unemployment and a respondent's exposure to newspapers.

Table 2 displays the results from two OLS regression models in which the local unemployment rates (in contexts with radii of 80 and 2,500 meters) and the municipality unemployment rate have been interacted with the respondent's newspaper consumption..$^{10}$ If the effect of contextual unemployment, whether measured at the municipality level or at a radius of 2,500 meters (both likely indicators of more aggregate contextual phenomena), is conditioned by exposure to local news, then we would expect a significant and

10. Note that the models are estimated with both municipality and time fixed effects. This specification means that we exploit only withinmunicipality within-year variation in unemployment and economic perceptions. This implies that we bypass unobserved time-invariant features of municipalities, e.g., various structural sociodemographic or political characteristics, as well as general time trends, which may influence the estimated relationship. See appendix $\mathrm{H}$ for a comparison of models with and without municipality fixed effects. 
728 / Reconsidering the Neighborhood Effect Martin Bisgaard, Peter Thisted Dinesen, and Kim Mannemar Sønderskov

Table 2. The Influence of Local Unemployment Measured in Contexts with a Radius of 80 and 2,500 Meters as Well as Municipality-Level Unemployment on Perceptions of the National Economy Conditional on Exposure to Newspapers

\begin{tabular}{|c|c|c|}
\hline & Model 1 & Model 2 \\
\hline \multirow[t]{2}{*}{ Local unemployment rate (80 meters) } & $-.112^{*}$ & $-.099^{*}$ \\
\hline & $(.046)$ & $(.044)$ \\
\hline \multirow[t]{2}{*}{ Local unemployment rate $(2,500$ meters $)$} & .245 & \\
\hline & $(.142)$ & \\
\hline \multirow[t]{2}{*}{ Municipality unemployment } & & -.066 \\
\hline & & $(.455)$ \\
\hline \multirow[t]{2}{*}{ Newspaper exposure } & .087 & .078 \\
\hline & $(.059)$ & $(.043)$ \\
\hline \multirow[t]{2}{*}{ LUR $(80$ meters $) \times$ newspaper exposure } & .230 & .197 \\
\hline & $(.172)$ & $(.165)$ \\
\hline \multirow[t]{2}{*}{ LUR $(2,500$ meters $) \times$ newspaper exposure } & $-.959^{*}$ & \\
\hline & $(.478)$ & \\
\hline \multirow[t]{2}{*}{ Municipality unemployment $\times$ newspaper exposure } & & $-2.245^{\star *}$ \\
\hline & & $(.800)$ \\
\hline \multirow[t]{2}{*}{ Constant } & $.594^{* * *}$ & $.620^{* * *}$ \\
\hline & $(.033)$ & $(.038)$ \\
\hline Municipality fixed effects & Yes & Yes \\
\hline Time fixed effects & Yes & Yes \\
\hline Additional controls ${ }^{\mathrm{a}}$ & Yes & Yes \\
\hline Adjusted $R^{2}$ & .174 & .174 \\
\hline$\sigma$ & .197 & .197 \\
\hline$F$ (added interactions) & 3.6 & 4.9 \\
\hline$p$ (added interactions) & .012 & .002 \\
\hline
\end{tabular}

Note. The table presents unstandardized OLS regression estimates; standard errors are in parentheses. Number of observations $=5,992$; number of survey rounds $=5$; number of municipalities $=313$. LUR $=$ local unemployment rate.

${ }^{a}$ Additional controls include political interest, age, sex, years lived at location, education, income, unemployment status, household unemployment, left-right orientation, and population density in the residential area. Estimates from the full model output can be found in appendix $\mathrm{H}$.

${ }^{*} p<.05$, two-sided test.

${ }^{* *} p<.01$, two-sided test.

${ }^{* * *} p<.001$, two-sided test.

negatively signed interaction term for these context sizes. As can be seen from the first column (model 1) and from figure 3, panel $B,{ }^{11}$ this is indeed the case: the effect of the local unemployment rate measured at a radius of 2,500 meters increases significantly (becomes more negative) with higher newspaper consumption $(p<.05$, model 1$)$. In terms of marginal effects, we observe a weak positive effect of

11. The univariate distribution of newspaper exposure is depicted along the $x$-axes of fig. 3 and shows, perhaps unsurprisingly, that the distribution of respondents is denser at the lower end of the scale. In appendix I.1, we show that the interaction effect still holds when the newspaper exposure scale is split at the median and treated as a binary variable in order to reduce the impact of extreme observations. the local unemployment rate $(2,500$ meters $)$ in the case of a complete absence of newspaper exposure (see panel $B$, fig. 3). Conversely, for individuals who are most exposed to newspapers, we see a stronger negative effect of the local unemployment rate (2,500 meters). Although fairly close, none of the marginal effects are significant at conventional levels. Nevertheless, the significant interaction term is in line with our prediction: local unemployment matters more (influences macroeconomic perceptions more negatively) in more aggregate contexts. Interestingly, we observe the opposite pattern for the marginal effect of the local unemployment rate measured in contexts with a radius of 80 meters (depicted in panel $A$, fig. 3). Here we find a significant negative effect of local unemployment rate ( 80 meters) for those who do not 

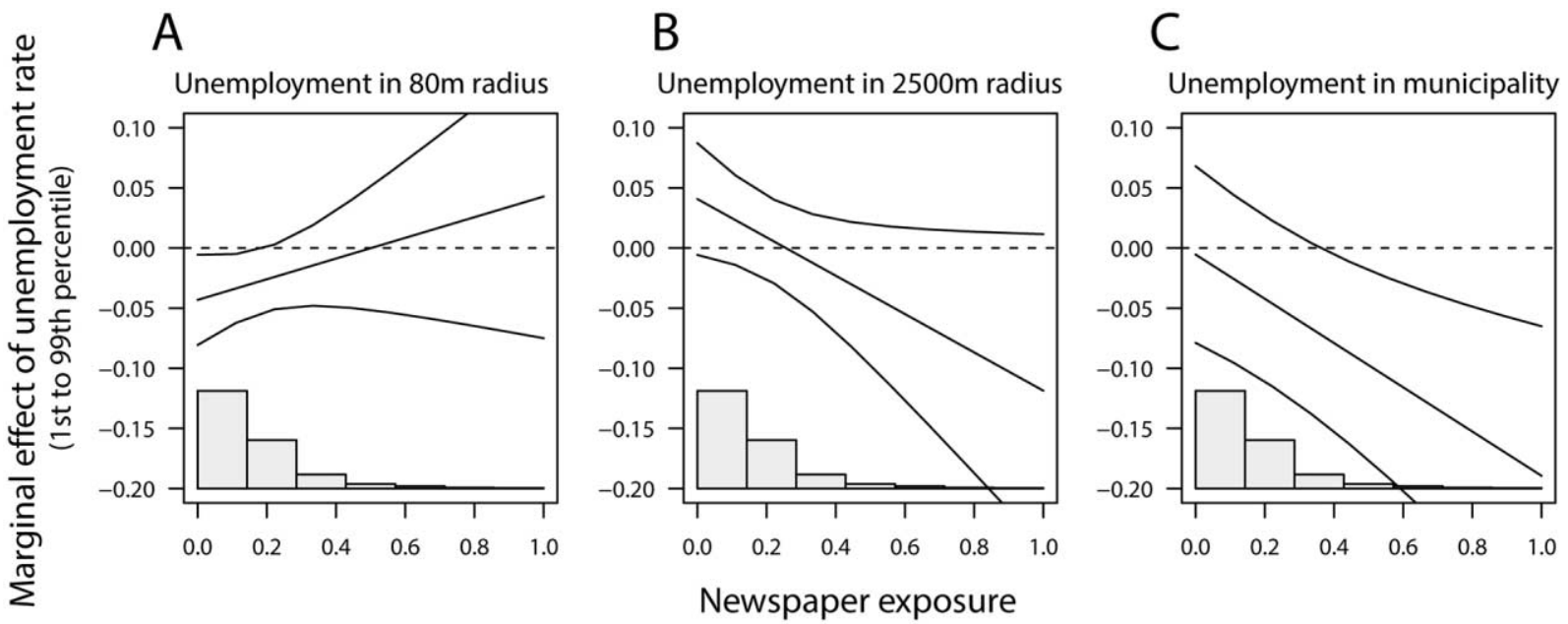

Figure 3. The marginal effect of unemployment measured in contexts with a radius of 80 meters $(A)$ and 2,500 meters (B) and at the muncipality level (C) conditional on exposure to newspapers. Marginal effects are based on the estimates from table 2, and they illustrate the change in economic perceptions when going from the 1st to the 9gth percentile on the unemployment measures. Marginal effects are depicted with a $95 \%$ confidence band. The histograms give the distribution of respondents on the newspaper exposure scale.

follow newspapers at all (the vast majority of the respondents). When newspaper exposure increases, the marginal effect of the local unemployment rate ( 80 meters) is reduced and eventually becomes insignificant. Note, however, that the interaction term is insignificant, which implies that the predicted change in the marginal effect of the local unemployment rate is very uncertain. While far from definitive given our limited statistical power, this finding is generally consistent with the idea that daily life experiences are especially consequential in the absence of mass-mediated information (Anderson and Roy 2011; Mutz 1998).

Returning to the influence of the more aggregate contexts, one would expect the same interaction effect between newspaper exposure and local unemployment at the municipality level as that observed in local contexts of a radius of 2,500 meters. In fact, if newspaper consumption moderates the influence of aggregate contextual unemployment (2,500 meters) because the latter reflects municipality characteristics covered by the local news media, then the interaction effect should, ceteris paribus, be stronger when we use the actual municipality unemployment rate. This is indeed the case, as evidenced by model 2. Again, there is a negatively signed and statistically significant interaction effect $(p<.01)$, indicating that the effect of municipality unemployment varies by newspaper exposure. ${ }^{12}$ More specifi-

12. In appendix I.2, we furthermore show that the interaction effect between municipality unemployment and exposure to newspapers is unaffected when we allow municipality unemployment to have different effects depending on a respondent's political interest, and her consumption of TV and radio. Hence, newspaper exposure is not simply picking up individual differences in political sophistication (as indicated by general media exposure) or political interest. cally, as evidenced by panel $C$ in figure 3, the marginal effect goes from essentially zero (and insignificant) for those who do not read newspapers to strongly and significantly negative for those who follow newspapers more closely.

\section{DISCUSSION AND CONCLUSION}

Mounting evidence suggests that voters infer macroeconomic conditions from objective circumstances in their everyday lives. Such findings are of crucial importance because they demonstrate that citizens' conceptions of abstract political issues cannot be reduced to elite influences and biases motivated by partisanship. Citizens, it seems, do obtain economically relevant information from their social contexts in that they use that information when forming perceptions of the national economy-a variable that has reached "canonical status in the political behavior literature" (Lewis-Beck and Nadeau 2011, 288).

However, existing work has been forced to use predefined and relatively aggregate measures of citizens' social contexts. As a consequence, there is little way of knowing whether such aggregate measures in fact capture social cues emanating from the local environment, nor can one pinpoint which specific aspects of this environment impact perceptions of the national economy. In short, there is little direct evidence to suggest that citizens actually do consider their local contexts, more specifically their immediate residential setting, when forming perceptions of national economic conditions.

Using highly disaggregated data about the proportion of unemployed people residing within a radius of down to 80 meters around a respondent's place of residence, we have put the proposed theoretical mechanism of residential in- 
fluence to a more appropriate empirical test. We found that the local unemployment rate in the immediate neighborhood significantly predicts perceptions of national economic conditions when we control for unemployment measured at a wider radius (2,500 meters), municipality and time fixed effects, left-right orientation, and a host of other individual-as well as contextual-level-characteristics. As such, our results suggest that the existing literature is right when assuming that local conditions inform perceptions about the national economy. However, our analyses also showed that aggregate measures of contextual unemployment used in most of the existing literature cannot straightforwardly be assumed to capture social influence from the immediate neighborhood. Specifically, we found that aggregate measures were not only poor reflections of an individual's immediate residential setting; they also appeared to capture a different theoretical mechanism, namely exposure to local news media coverage. While the latter conclusion is of a more tentative nature, our analyses clearly show that future studies on contextual effects should consider whether an observed relationship is actually reflecting direct social influence or rather exposure to alternative sources of information pertaining to larger political units.

In this paper, we have focused narrowly on how the residential microcontext affects economic perceptions under the widely held-and often confirmed-assumption that economic perceptions influence evaluations of governments and, ultimately, voting behavior. Thus, an even stronger indication of the importance of the microcontext would be to show that its effects in fact extend to these purported downstream consequences of macroeconomic perceptions. In supplementary analyses reported in appendix J, we show that this is indeed the case: variation in unemployment in people's residential microcontexts also affects approval of the incumbent government and vote intentions. This is a strong indication of the fertility of further probing the microcontextual underpinnings of these and other political attitudes and behaviors as suggested in the study of social trust by Dinesen and Sønderskov (2015).

Beyond establishing that the effect of the microcontext in fact generalizes to other forms of political behavior, the broader implications of this study are threefold. First, dating back to Kramer (1983), a persistent puzzle has been how variation in citizens' perceptions of the same macroeconomy can reflect little more than guesswork and partisan imagery. Our results suggest that these differences can be meaningful and, in fact, seem to originate in the social surroundings citizen's observe in their everyday life (see also Duch et al. 2000). Second, and relatedly, this study confirms the value of incorporating social context in models of pub- lic opinion (Huckfeldt 2014). Like most other studies, however, we have only uncovered one aspect of how an individual's social context may influence his or her conception of politics. For example, one particularly fruitful avenue for future research would be to extend research on the effects of social contexts beyond the rather narrow conceptualization of the neighborhood. While people are certainly tied to their place of residence, and thus naturally exposed to social stimuli emanating from the neighborhood, the concept of a social context is of course much broader. We are connected to our coworkers, family, friends, and our friends' friends, and trying to uncover how different forms of social connectivity influences people's inferences about collective phenomena, such as the national economy, may not only be empirically but also theoretically rewarding. Finally, in our effort to uncover the impact of context, we have tried to hold constant other important factors such as partisanship. Yet it would be worthwhile for future studies to integrate these factors more dynamically in models of contextual influence. For example, do vivid experiences of unemployment within one's social vicinity place certain constraints on wishful partisan thinking and on party elites' ability to sway public opinion? If so, politics may not be as abstract and symbolic as conventional wisdom suggests.

\section{ACKNOWLEDGMENTS}

Kasper Møller Hansen, Jacob Gerner Hariri, Dan Hopkins, Gaurav Sood, Rune Slothuus, Rune Stubager, and participants at the Political Economy Workshop at Stanford University, as well as the Political Behavior Research Section at Aarhus University, provided helpful comments and suggestions on earlier drafts. We also thank our anonymous reviewers for providing feedback that greatly improved the manuscript.

\section{REFERENCES}

Aidt, Toke S. 2000. "Economic Voting and Information.” Electoral Studies 19:349-62.

Anderson, Cameron D., and Jason Roy. 2011. "Local Economies and National Economic Evaluations: How the Local Economic Environment Influences National Economic Perceptions.” Electoral Studies 30 (4): 795-803.

Angrist, Joshua D., and Jörn-Steffen Pischke. 2008. Mostly Harmless Econometrics: An Empiricist's Companion. Princeton, NJ: Princeton University Press.

Ansolabehere, Stephen, Marc Meredith, and Erik Snowberg. 2011. "Sociotropic Voting and the Media." In John Aldrich and Kathleen McGraw, eds., Improving Public Opinion Surveys. Princeton, NJ: Princeton University Press, 175-93.

Ansolabehere, Stephen, Marc Meredith, and Erik Snowberg. 2014. "MecroEconomic Voting: Local Information and Micro-Perceptions of the Macro-Economy." Economics and Politics 26 (3): 380-410. 
Bartels, Larry M. 2002. "Beyond the Running Tally: Partisan Bias in Political Perceptions." Political Behavior 24 (2): 117-50.

Baybeck, Brady, and Scott D. McClurg. 2005. "What Do They Know and How Do They Know It?” American Politics Research 33 (4): 492-520.

Bisgaard, Martin. 2015. "Bias Will Find a Way: Economic Perceptions, Attributions of Blame, and Partisan-Motivated Reasoning during Crisis." Journal of Politics 77 (3): 849-60.

Bishop, Bradford H. 2013. "Drought and Environmental Opinion: A Study of Attitudes toward Water Policy." Public Opinion Quarterly 77 (3): 798-810.

Books, John, and Charles Prysby. 1999. "Contextual Effects on Retrospective Economic Evaluations.” Political Behavior 21 (1): 1-16.

Boomgaarden, Hajo G., Joost van Spanje, Rens Vliegenthart, and Claes H. de Vreese. 2011. "Covering the Crisis: Media Coverage of the Economic Crisis and Citizens' Economic Expectations." Acta Politica 46 (4): 353-79.

Buch, Roger, and Klaus Levinsen. 2007. "Nye kommuner, nye medier og borgernes syn på valgkampen" [New municipalities, new media outlets, and citizens' perceptions of the election campaign]. In Roger Buch and Jergen Elklit, eds., Nye kommunalvalg? Odense: Syddansk Universitetsforlag, 63-78.

Cho, Wendy K. Tam, and Thomas J. Rudolph. 2008. "Emanating Political Participation: Untangling the Spatial Structure behind Participation.” British Journal of Political Science 38 (2): 273-89.

Conover, Pamela Johnston, Stanley Feldman, and Kathleen Knight. 1987. "The Personal and Political Underpinnings of Economic Forecasts." American Journal of Political Science 31 (3): 559-83.

Delli Carpini, Michael X., and Scott Keeter. 1996. What Americans Know about Politics and Why It Matters. New Haven, CT: Yale University Press.

Dinesen, Peter T., and Kim M. Sønderskov. 2015. "Ethnic Diversity and Social Trust: Evidence from the Micro-Context." American Sociological Review 80 (3): 550-73.

Duch, Raymond M., Harvey D. Palmer, and Christopher J. Anderson. 2000. "Heterogeneity in Perceptions of National Economic Conditions." American Journal of Political Science 44 (4): 635-52.

Egan, Patrick J., and Megan Mullin. 2012. "Turning Personal Experience into Political Attitudes: The Effect of Local Weather on Americans' Perceptions about Global Warning." Journal of Politics 74 (1): 796-809.

Elmelund-Præstekær, Christian, and David H. Hopman. 2013. "Vælgernes kilder til information om kommunalvalget" [Voters' sources of information about the municipal election]. In Jorgen Elklit and Ulrik Kjaer, eds., KV09. Odense: University Press of Southern Denmark, 123-36.

ESS (European Social Survey). 2014. "Data and Documentation by Round/ Year." http://www.europeansocialsurvey.org/data/round-index.html (accessed January 1, 2014).

Evans, Geoffrey, and Robert Andersen. 2006. "The Political Conditioning of Economic Perceptions." American Journal of Political Science 68 (1): 194-207.

Fraile, Marta, and Shanto Iyengar. 2014. "Not All News Sources Are Equally Informative: A Cross-National Analysis of Political Knowledge in Europe." International Journal of Press Politics 19 (3): 275-94.

Gerber, Alan S., and Gregory A. Huber. 2010. "Partisanship, Political Control, and Economic Assessments." American Journal of Political Science 54 (1): 153-73.

Goidel, Robert K., and Ronald E. Langley. 1995. "Media Coverage of the Economy and Aggregate Economic Evaluations: Unvcovering Evidence of Indirect Media Effects." Political Research Quarterly 48 (2): 313-28.

Healy, Andrew, and Gabriel S. Lenz. 2014. "Presidential Voting and the Local Economy." Unpublished manuscript, Loyola Marymount University.

Hetherington, Marc J. 1996. "The Media's Role in Forming Voters' National Economic Evaluations in 1992." American Journal of Political Science 40 (2): 372-95.
Higgins, E. Tory, and Gillian King. 1981. "Accessibility of Social Constructs: Information Processing Consequences of Individual and Contextual Variability." In Nancy Cantor, and J. F. Kihlstrom, eds., Personality, Cognition, and Social Interaction. Hillsdale, NJ: Eribaum, 69-121.

Hopkins, Daniel J. 2010. "Politicized Places: Explaining Where and When Immigrants Provole Local Opposition." American Political Science Review 104 (1): 40-60.

Huckfeldt, Robert. 2014. "Networks, Contexts, and the Combinatorial Dynamics of Democratic Politics.” Political Psychology 35:43-68.

Huckfeldt, Robert, and John Sprague. 1987. "Networks in Context." American Political Science Review 81 (4): 1197-1216.

Iyengar, Shanto, James Curran, Anker Brink Lund, Inka SalovaaraMoring, Kyu S. Hahn, and Sharon Coen. 2010. "Cross-National versus Individual-Level Differences in Political Information." Journal of Elections, Public Opinion and Parties 20 (3): 291-309.

Iyengar, Shanto, and Donald R. Kinder. 1987. News That Matters. Chicago: University of Chicago Press.

Kinder, Donald R., and D. Roderick Kiewiet. 1981. "Sociotropic Politics: The American Case." British Journal of Political Science 11 (2): 129-61.

Kramer, G. H. 1983. "The Ecological Fallacy Revisited.” Aggregate- versus Individual-Level Findings on Economics and Elections, and Sociotropic Voting." American Political Science Review 77 (1): 92-111.

Lazarsfeld, Paul F., Bernard Berelson, and Hazel Gaudet. 1944. The People's Choice: How the Voter Makes Up His Mind in a Presidental Campaign. New York: Columbia University Press.

Lewis-Beck, Michael S., and Richard Nadeau. 2011. "Economic Voting Theory: Testing New Dimensions.” Electoral Studies 30 (2): 288-94.

Lewis-Beck, Michael, and Mary Stegmaier. 2007. "Economic Models of Voting." In Russell J. Dalton and Hans-Dieter Klingemann, eds., The Oxford Handbook of Political Behavior. Oxford: Oxford University Press, 518-37.

Linn, Suzanna, Jonathan Nagler, and Marco A. Morales. 2010. "Economics, Elections, and Voting Behavior." In Jan E. Leighley, ed., The Oxford Handbook of American Elections and Political Behavior. Oxford: Oxford University Press, 375-96.

Lund, Anker B. 2002. Den redigerende magt [The editing power]. Aahaus: Aarhus University Press.

Miller, Joanne M., and David A. M. Peterson. 2004. "Theoretical and Empirical Implications of Attitude Strength." Journal of Politics 66 (3): 847-67.

Mondak, Jeffery J., Diana C. Mutz, and Robert Huckfeldt. 1996. "Persuasion in Context: The Multilevel Structure of Economic Evaluations." In Diana C. Mutz, Paul M. Sniderman, and Richard A. Brody, eds., Political Persuasion and Attitude Change. Ann Arbor: University of Michigan Press, 249-66.

Moore, Ryan T., and Andrew Reeves. 2015. "Milieu: Defining Political Context with Geolocation Data." Working paper.

Mutz, Diana C. 1992. "Mass Media and the Depoliticization of Personal Experience." American Journal of Political Science 36 (2): 483-508.

Mutz, Diana C. 1998. Impersonal Influence: How Perceptions of Mass Collectives Affect Political Attitudes. Cambridge: Cambridge University Press.

Newman, Benjamin J., Yamil Velez, Todd K. Hartman, and Alexa Bankert. 2014. "Are Citizens 'Receiving the Treatment'? Assessing the Validity of Contextual Theories of Public Opinion and Political Behavior." Political Psychology 36 (1): 123-31.

Newton, Kenneth. 1999. "Mass Media Effects: MObilization or Media Malaise?” British Journal of Political Science 29 (4): 577-99.

Norris, Pippa. 2004. "From the Civic Culture to the Afrobarometer." Newsletter for the American Poitical Science Association Section in Comparative Politics 15:6-11.

Oliver, J. Eric, and Tali Mendelberg. 2000. "Reconsidering the Environmental Determinants of White Racial Attitudes." American Journal of Political Science 44 (3):574-89. 
732 / Reconsidering the Neighborhood Effect Martin Bisgaard, Peter Thisted Dinesen, and Kim Mannemar Sønderskov

Podsakoff, Philip M., Scott B. MacKenzie, Jeong-Yeon Lee, and Nathan P. Podsakoff. 2003. "Common Method Biases in Behavioral Research." Journal of Applied Psychology 88 (5): 879-903.

Popkin, Samuel. 1991. The Reasoning Voter: Communication and Persuasion in Presidential Campaigns. Chicago: University of Chicago Press.

Price, Vincent, and John Zaller. 1993. "Who Gets the News? Alternative Measures of News Reception and Their Implications for Research." Public Opinion Quarterly 57 (2): 133-64.

Putnam, Robert D. 2007. "E Pluribus Unum: Diversity and Community in the Twenty-First Century." Scandinavian Political Studies 30 (2): 137-74.

Reeves, Andrew, and James G. Gimpel. 2012. "Ecologies of Unease: Georgraphic Contexts and National Economic Evaluations.” Political Behavior 34 (3): 507-34.

Robinson, John P., Mark R. Levy, Dennis K. Davis, William G. Woodall, Michael Gurevitch, and Haluk Sahin. 1986. The Main Source: Learning from Television News. Beverly Hills, CA: Sage.

Rudolph, Thomas J., and Elizabeth Popp. 2010. "Race, Environment, and Interracial Trust." Journal of Politics 72 (1): 74-89.
Serritzlew, Søren, and Peter B. Mortensen. 2007. "Medierne set fra rådhuset" [The media seen from the city-hall]. In Roger Buch and Jørgen Elklit, eds., Nye kommunalvalg? Odense: University Press of Southern Denmark, 191-204.

Soroka, Stuart N. 2006. "Good News and Bad News: Assymetric Responses to Economic Information.” Journal of Politics 68 (2): 372-85.

Stevenson, Randolph T., and Raymond Duch. 2013. "The Meaning and Use of Subjective Perceptions in Studies of Economic Voting." Electoral Studies 32 (2): 305-20.

Thygesen, Lau Caspar, Camilla Daasnes, Ivan Thaulow, and Henrik BrønnumHansen. 2011. "Introduction to Danish (Nationwide) Registers on Health and Social Issues." Scandinavian Journal of Public Health 39 (7): 12-16.

Weatherford, M. S. 1983. "Economic Voting and the 'Symbolic Politics' Argument.” American Political Science Review 77:158-74.

Wong, Cara, Jake Bowers, Tarah Williams, and Katherine Drake Simmons. 2012. "Bringing the Person Back In: Boundaries, Perceptions, and Racial Context." Journal of Politics 74 (4): 1153-70.

Zaller, John R. 1992. The Nature and Origins of Mass Opinion. Cambridge: Cambridge University Press. 